\title{
SEEDS COUNTING DEVICE BASED ON LIGHT REFLECTANCE OPTOELECTRONIC FIELD DETECTION
}

\author{
El Attar, M. Z.
}

\begin{abstract}
New light reflecting optoelectronic fields counter capable of detecting and counting free falling object with equivalent length/diameter $\geq 0.5 \mathrm{~mm}$ in seeder delivering tube was developed and tested to evaluate seeding rate. The performance of the device is not affected by the shape, and color of the counted objects. Accuracy is dependent on seeding rate, and falling seeds overlapping. The device can count falling seeds with 0.11 sec apart accurately, or seeding at speed $\leq 7 \mathrm{~km} / \mathrm{h}$ within $5 \mathrm{~cm}$ diameter of seeds delivering tube
\end{abstract}

Keywords: seed counter, object counter, seeding rate, metering system..

\section{INTRODUCTION}

$\mathrm{P}$ lanters, seeders, and driller calibration is a mean of improving machine performance and controlling input costs by verifying the rate of delivery of a crop input such as fertilizer, herbicide, and seed. Traditional seed drills do a poor job of distributing seed evenly, resulting in clumping of seed, and leaving large gaps within the row. A planter allows for precise seed metering, resulting in more uniform plant intensity. It also allows for better crop growth, and depth control. Ordinary ways of calibration are generally tedious and time consuming. In addition, the recent seed counters can do the calibration in easy and accurate way, monitor the seeding process during farming to eliminate uneven stands and help control seeding costs by achieving targeted seeding rates.

Small-scale yield studies, germination tests, controlled plantings, and packaging often require the counting of large numbers of seeds. A photosensitive detector and a vacuum pickup were used to count individual seeds and give a direct digital readout. The count rate is limited only by how quickly the seeds can be fed through the counting tube without clogging or having touching each other.

\footnotetext{
"Literature of Agric. Eng., Ain Shams Univ., Fac. Agric., Agric. Eng. Dept. Cairo, Egypt.
} 
This counting, eliminates operator error, and reduces operator fatigue (Fisher and Brown, 1973).

By use of precision seeding equipment and good seed, a uniform seedling stand can be obtained. This will improve the ability of the machine to harvest the plants and improve the efficiency of the transplanted operators to handle the plants without producing skips. In addition, improved techniques of irrigation after transplanting and improved watering of the seedlings after harvest need to be developed to minimize seedlings exposure to stress damage (Mishoe and Guzman, 1977).

Awady et al. (1998) developed a new acoustical technique, and computer software for counting objects and agricultural materials. Raheman et al. (2003) studied the performance of a light interference counting technique for wheat, mustard, and maize seeds in a test-rig developed for testing different metering mechanisms used in seed drills and planters.

Jayan et al. (2004) stated that both roundness and sphericity affect seed flow through the various components of planters, Seed flow through a planter is dependent on size, shape, sphericity, true density, and angle of repose of seeds.

Other researchers used an optoelectronic sensor for measuring the seed spacing of planters in the laboratory for seeds of size larger than $3 \mathrm{~mm}$ in diameter. They found that sensor did not work for the size of seed less than $3 \mathrm{~mm}$ in diameter. No attempt has been made to sense the seed flow in the seed delivery tube by which the operator can know the workability of the seed drill and planter. These differences were mainly because of the inability of the sensor to sense the multiple seed droppings in a short span of time. (Raheman and Singh, 2003).

The aim of this work is to build an accurate reflectance light optoelectronic object counting system capable of counting and calibrating small agricultural materials, especially seeds in deliver tube for Lab and field operations. 


\section{MATERIALS AND METHODS}

\section{Circuit description:}

The reflective light object detection and Counting device consisted of two circuits: A) object detection and counting unit, and B) event counting unit: universal 4 digit up/down counter with comparator

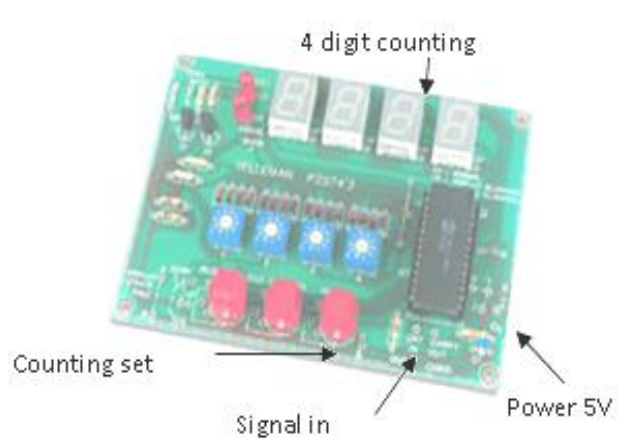
(Velleman-kit k2574, Belgium), Fig.1.The object detection and Fig. (1): Signal counting circuit. counting circuit was constructed from three stages: (1) detection and amplifying stage, (2) signal level detection stage, and (3) signal time delay stage, as shown in Fig.2.

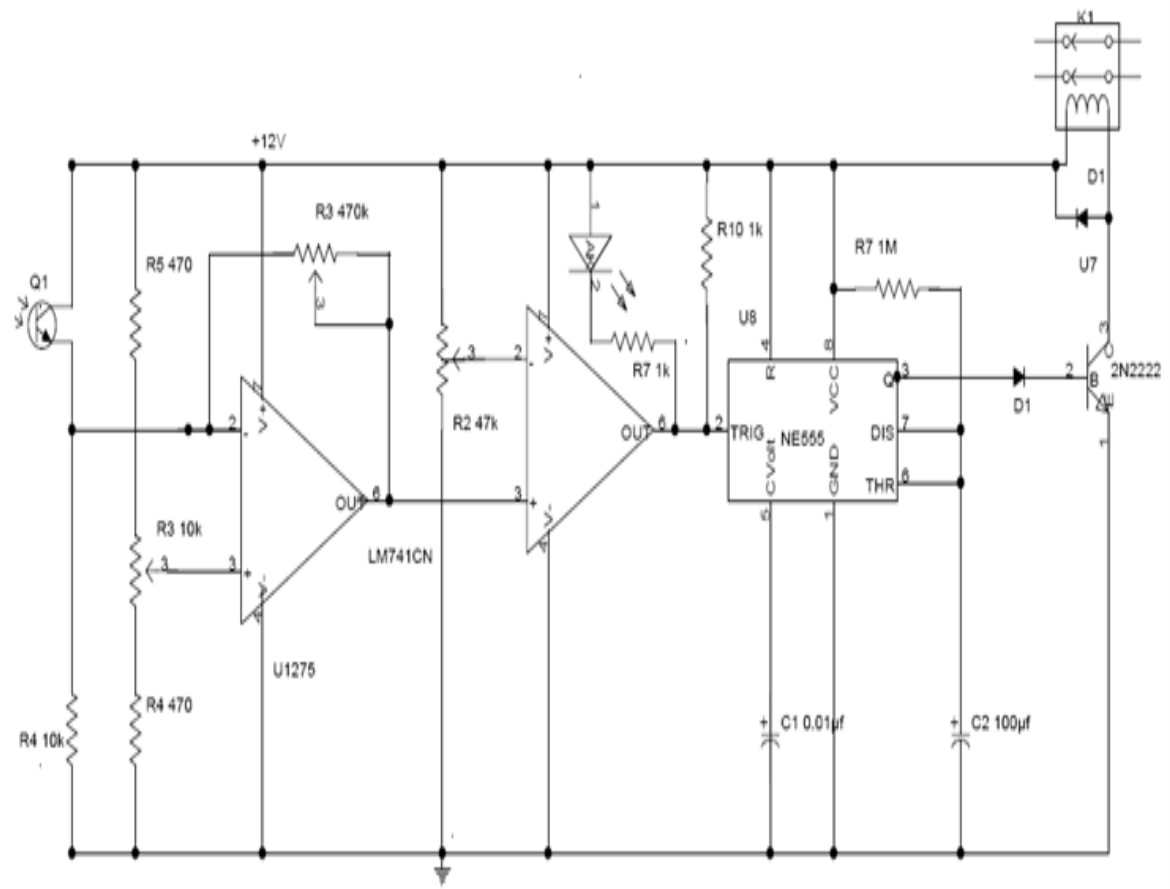

Fig. (2): Circuit diagram of object detection and counting device. 
All three stages were set in a simple enclosure as viewed in Fig.3.

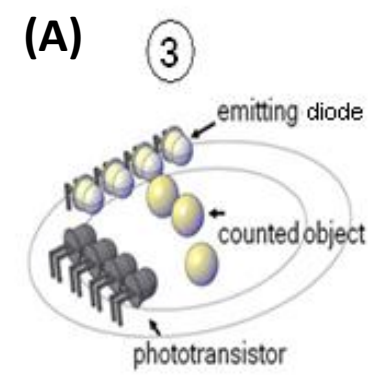

(1) Seeds delivering tube

(4) Sample outlet hopper

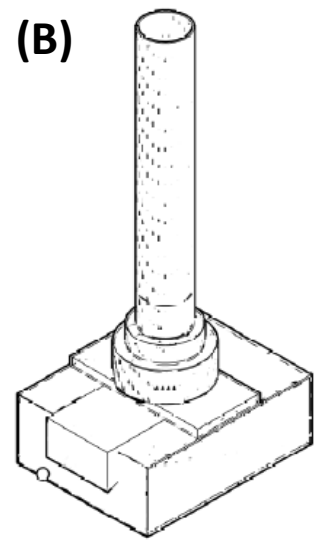

(2) Sensor holder

(5) Circuit enclosure box

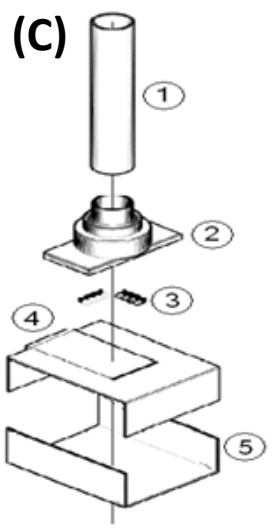

(3) Light sensors and emitting diodes

Fig. (3): (A) IR LEDs and phototransistors set, (B) Schematic diagram of the object counter, and (C) Assembly diagram of the object counter.

Four infrared light emitting diodes (IR LEDs) were used in series, as a source of light, and need at least $8 \mathrm{~V}$, according to the equation:

$$
\mathrm{V}_{\mathrm{L}}=2 \mathrm{v}+2 \mathrm{v}+2 \mathrm{v}+2 \mathrm{v}=8 \mathrm{v}
$$

When using a supply voltage $\left(\mathrm{V}_{\mathrm{S}}\right.$ as $12 \mathrm{~V}$ (Fig. 4), and the current of emitting diode $15 \mathrm{~mA}$, load resistor will be:

$$
R=\frac{(\mathrm{VS}-\mathrm{VL})}{\mathrm{I}}=\frac{(12-8)}{0.015}=266.7 \Omega .
$$

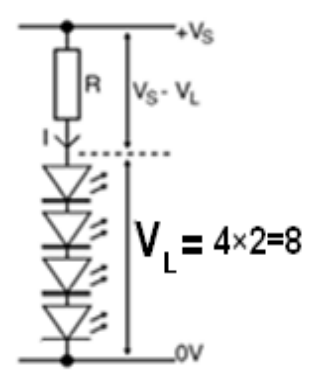

Fig.(4): IR LEDs array

Where V: is electrical potential, $\mathrm{V}_{\mathrm{s}}$ : source potential, $\mathrm{v}_{\mathrm{l}}$ : load potential, $\mathrm{I}$ : electrical current, and $\mathrm{R}$ : load resistance in ohms.

The emitting diodes array was able to cover any falling object in area/field of $5 \mathrm{~cm}$ diameter, Fig.5. The working detection area/ field can be extended by using additional LEDs and phototransistor. 


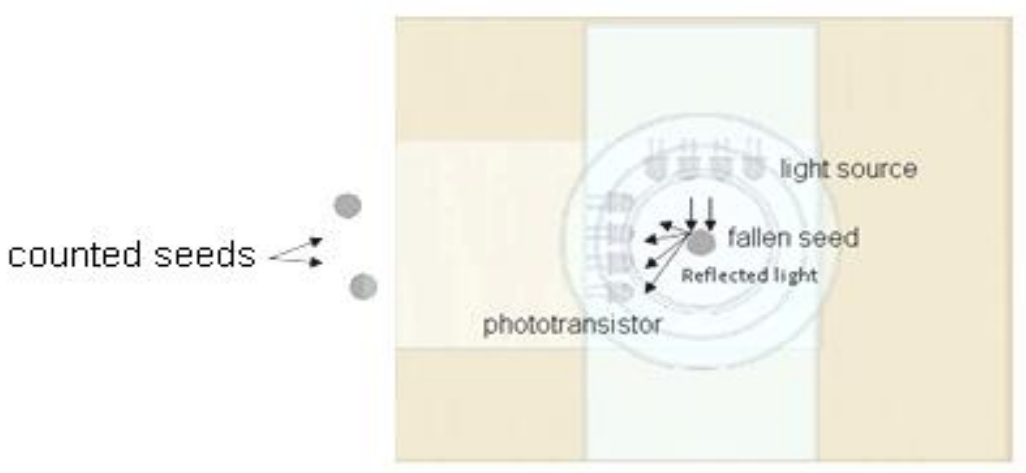

Fig. (5): Illustration of counting process light reflected by the seed on phototransistors

(Top view).

\section{Eliminating signal interference:}

Object detection by reflected light from falling seed can interfere with reflected light from surrounding materials. Interference light absorbing materials, was tested to absorb reflected infrared light from surrounding and sensor enclosure internal wall. A test set shown in Fig. 6, was used to examine reflectance from mirror (reference), gray plastic, pale dark black paint plastic, pale dark black sponge, and pale dark black sponge with laser toner ink layer. The set consists of 40 Watt incandescent tungsten lamp, and EXTECH instruments light meter model 407026, enclosed in a black light box for measuring intensity of reflected light.

Light source

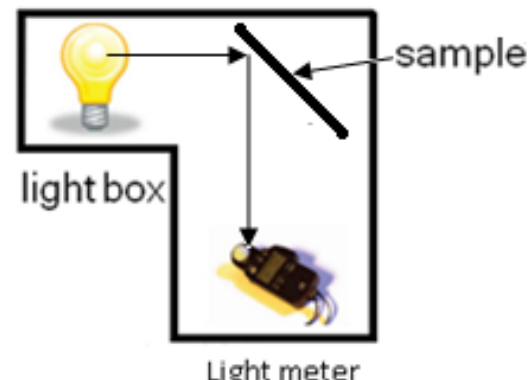

Light meter

Fig. (6): Schematic of reflectivity test set.

\section{Investigation of counting errors to shape irregularity and overlap:}


In case of sensing irregular seed shape and overlapping, six cases of overlapping and shape irregularity were investigated as shown in Fig. 7. The experiments were conducted by standard round plastic balls with different colors and sizes. It was carried out with cases of tangent, 25\%, and 50\% overlapping for both falling case in horizontal and vertical direction, for different ball size $(7,11$, and 13mm) and colors (white, golden yellow, dark blue, and black).
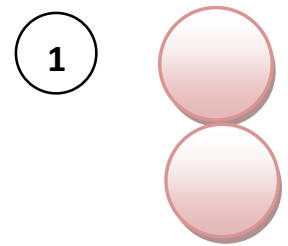

Vertical tangent

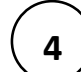

4
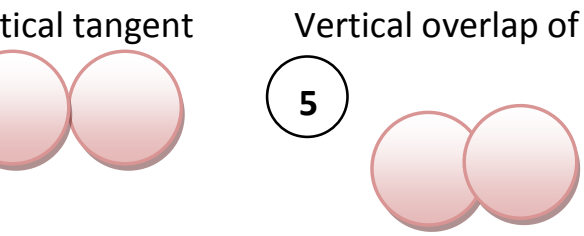

Horizontal tangent Horizontal overlap of $25 \%$

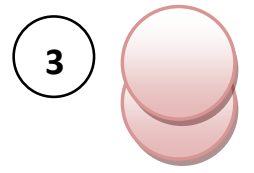

Vertical overlap of $50 \%$
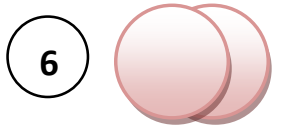

Horizontal overlap of $50 \%$

Fig.(7): Counting test with standard ball for overlap and irregularity cases.

For signal studies, data were collected with a PC data acquisition of 48k sample/sec and processed with "Cool Edit pro" software (version 2.0 products from Syntrillium software Co.).

\section{Accuracy of seed counter:}

Accuracy of seed counting process was tested in lab by an experimental seed metering mechanism, powered by a geared head DC motor and used to simulate the planting process at forward speeds of 1.5, 3.0, 4.5, and 6 $\mathrm{km} / \mathrm{h}$. The seed metering mechanism consists of a fixed disk to the motor, with seed release hole $(19 \mathrm{~mm}$ diameter) centrally aligned to a changeable rotating disk with 12 seed cell. The rotating disk can be changed according to the type of counted seed with seed cell diameter of 10,16 , and $19 \mathrm{~mm}$, Fig. 8 . 
The DC geared head motor rotation speeds were calculated with assumption of seeding at $25 \mathrm{~cm}$ seed to seed space, which gives 4000 seed $/ \mathrm{km}$.

(A)

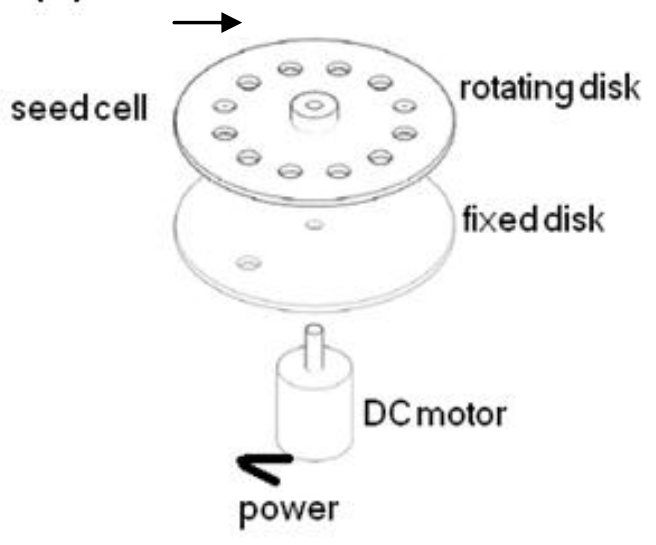

(B)

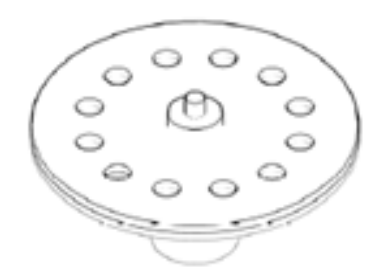

Fig. (8): (A) Assembly diagram of seed metering mechanism, (B) Schematic diagram of seed metering mechanism.

\section{RESULTS AND DISCUSSION}

\section{Eliminating signal interference:}

The interference of reflected infrared light form internal wall and surrounding materials with counted light signals of seeds was eliminated by using a pale dark black sponge coated by thin layer of laser printer toner ink, around the sensor light detection set. The absorbing material was capable of absorbing $97 \%$ of the interfering reflected light and correct counting errors caused by reflected light form non-target materials as shown in Fig.9.

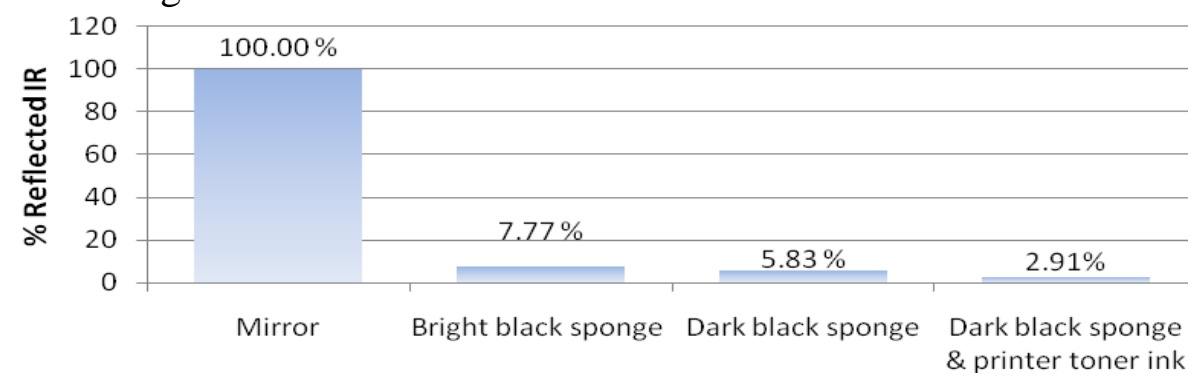

Fig .(9): Percentage of absorbing IR light source for different types of materials. 


\section{Counting errors to irregular shape and overlap:}

For verifying the most suitable circuit stage to signaling the seeds counting process, a signal was taken from each stage and processed by Cool Edit pro software. The difference between the peak to peak signals due to falling object size (7, and 13mm), is illustrated in Fig.10-A, and color in Fig.10-B. It was found that signals detected from threshold stage are independent for color and size parameters of the detected object.

(A)

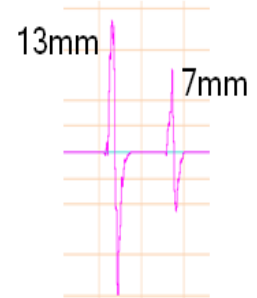

(B)

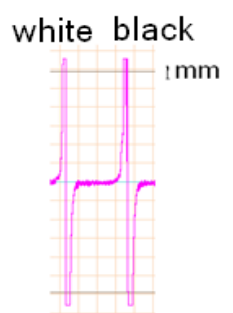

Fig. (10): Falling object signal according to (A) Size, and (B) color of the detected object.

Result shows no change in counting accuracy due to the shape, color, and size for all examined six cases of irregular shape and counted object overlapping (Fig.11).

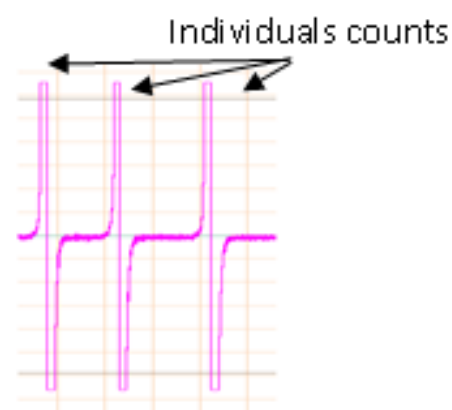

$25 \%$ Vertical overlapping

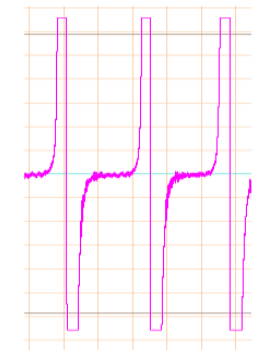

$50 \%$ Horizontal

overlapping

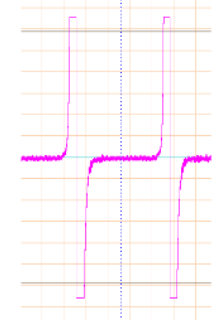

$50 \%$ Vertical overlapping

Fig. (11): Influence of falling object overlapping percentage.

\section{Accuracy of seed counter:}

Seed metering mechanism used in the lab experiments was calibrated to simulate planter's field forward speeds by $1.5,3.0,4.5$, and $6 \mathrm{~km} / \mathrm{h}$ as shown in Fig.12. 


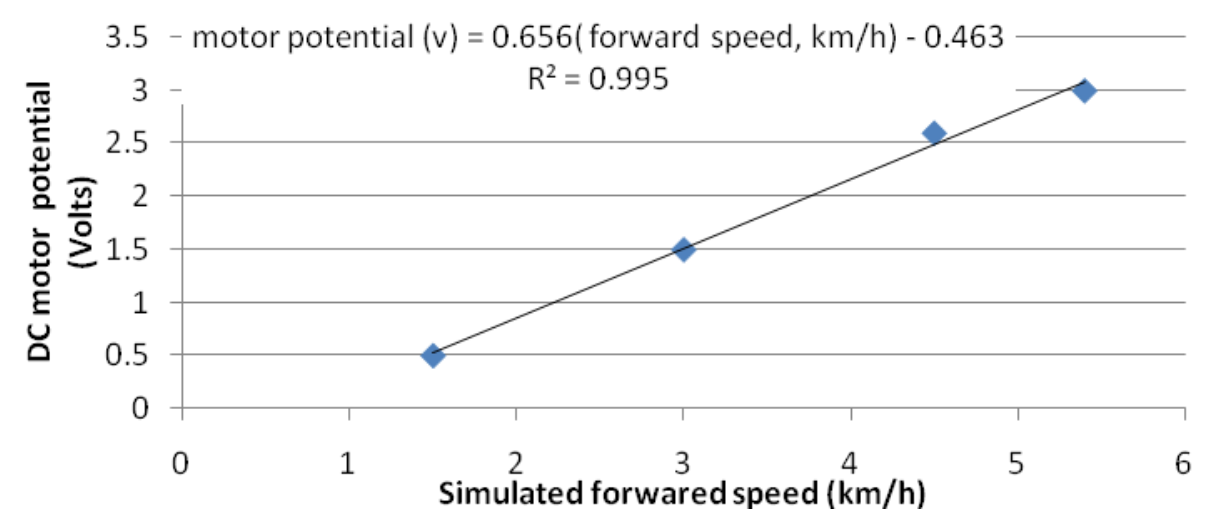

Fig. (12): DC motor calibration of the metering mechanism.

The light reflectance counter used to determine number of different types of falling seeds was $100 \%$ accurate at tested speeds of 1.5, 3.0, 4.5, and 6 $\mathrm{km} / \mathrm{h}$, for all type of tested seeds as shown in Fig.13.

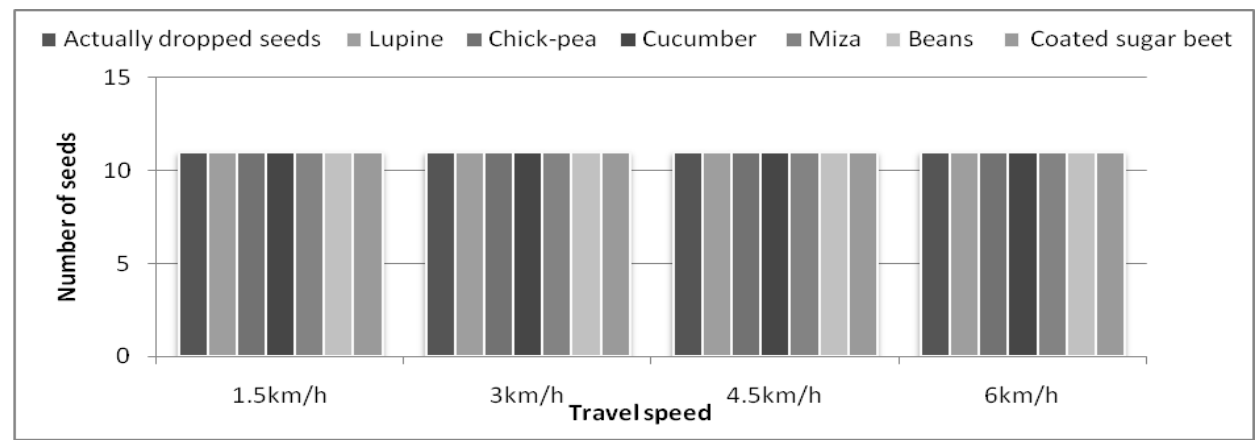

Fig.(13): Performance of object counting device for different type of seeds and forward speeds.

\section{CONCOLUSIONS}

Using detection and counting device will enhance the operation and performance of different agricultural processes. A planter could be observed and calibrated by the seed counting device at speed $\leq 6 \mathrm{~km} / \mathrm{h}$ with $100 \%$ accuracy. There was no influence of seed shape, and color on the accuracy of counting process. The device was able to detect object of equivalent length/diameter $\geq 0.5 \mathrm{~mm}$ within $5 \mathrm{~cm}$ diameter of seeds delivering tube and can extended by adding more LEDs and phototransistors. 


\section{REFERANCIES}

Awady M.N., El Kabany, A.G.; and El Attar, M.Z., 1998, Software acoustic technique for object detection and counting, the $6^{\text {th }}$ conf. MISR Soc. Ag. Eng.:219-226.

Fisher H. D., and Brown M. J., 1973, A photoelectric seed counter'. Agronomy, 65: 82-684.

Jayan P., and Kumar V. ,2004, Planter design in relation to the physical properties of seeds. Tropical Agric. , 42 (1-2): 69-71.

Mishoe J. W., and Guzman, V. L., 1977, Evaluation of the ifas celery seedling harvester using precision seeded plants, Proc. Fla. State Hort. Soc. , 90: 404-407..

Raheman H., and Singh, U., 2003, A sensor for seed flow from seed metering mechanisms. IE (I) JournalŚ $A G, 84$.

\section{الملخص العربيى}

\section{جهاز لعد البذور بالأشعة الضوئية المنعكسة عن الأجسام

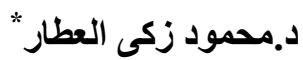

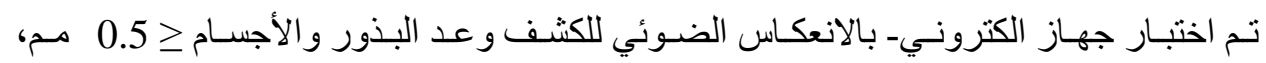

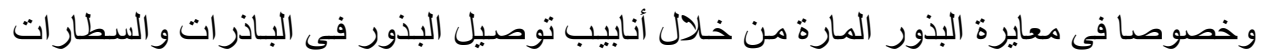

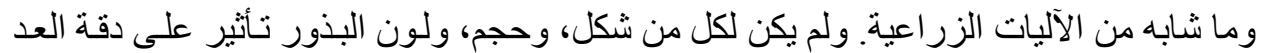

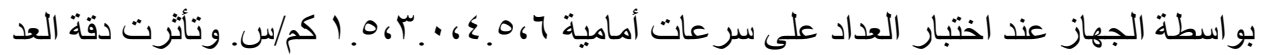

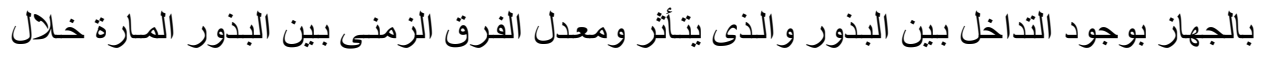

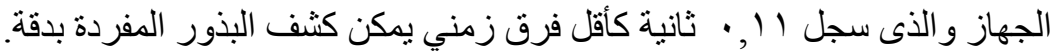
الكلمات المفتاحية: عدادات الحبوب، أجهزة العد الضوئية، معايرة الباذرات.

*مدرس الهندسة الزر اعية، قسم الهندسة الزراعية، كلية الزراعة، جامعة عين شمس. 